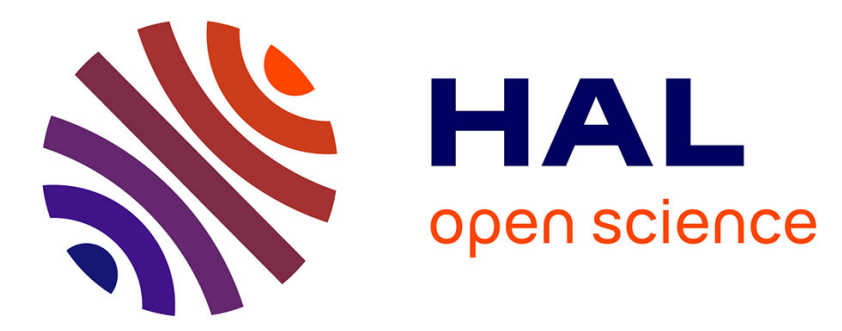

\title{
Metal-Free Visible-Light-Mediated Aromatization of 1,2-Dihydronaphthalenes
}

\author{
Fatima Rammal, Annie-Claude Gaumont, Sami Lakhdar
}

\section{To cite this version:}

Fatima Rammal, Annie-Claude Gaumont, Sami Lakhdar. Metal-Free Visible-Light-Mediated Aromatization of 1,2-Dihydronaphthalenes. European Journal of Organic Chemistry, 2020, 2020 (10), pp.1482-1485. 10.1002/ejoc.201901410 . hal-03101170

\section{HAL Id: hal-03101170 \\ https://hal.science/hal-03101170}

Submitted on 7 Jan 2021

HAL is a multi-disciplinary open access archive for the deposit and dissemination of scientific research documents, whether they are published or not. The documents may come from teaching and research institutions in France or abroad, or from public or private research centers.
L'archive ouverte pluridisciplinaire HAL, est destinée au dépôt et à la diffusion de documents scientifiques de niveau recherche, publiés ou non, émanant des établissements d'enseignement et de recherche français ou étrangers, des laboratoires publics ou privés. 


\title{
Metal-Free Visible-Light-Mediated Aromatization of 1,2- Dihydronaphthalenes
}

\author{
Fatima Rammal, Annie-Claude Gaumont, and Sami Lakhdar*
}

\begin{abstract}
A series of polyaromatic naphthalenes have been synthesized through the dehydrogenation of the corresponding 1,2-dihydroarylnaphthalenes by using 9-mesityl-10methylacridinium perchlorate as a photocatalyst and diphenyliodonium triflate as an external oxidant under visible light irradiation. The reaction proceeds smoothly under metal-free conditions and tolerates some functionalities. Interestingly, the reaction is also amenable to the aromatization of tetrahydronaphthalenes and fair conversions were obtained. Preliminary mechanistic investigations have been conducted and a reasonable mechanism is proposed.
\end{abstract}

Polyaromatic naphthalenes are privileged scaffolds that can be found in numerous biologically active molecules and functional materials. ${ }^{[1]}$ In this regard, the development of straightforward and practically simple protocols to access those molecules has been and still is the subject of numerous studies. ${ }^{[2]}$ Typically, most synthesis of those molecules relay on the formation of one or two six-membered rings by classical methods (Diels-Alder or Friedel-Crafts) or via metalcatalyzed cyclizations. ${ }^{[3]}$ They can also be accessed through the aromatization of 1,2dihydronaphthalenes. The latter approach has gained remarkable interest obviously due to the development of straightforward methods for the synthesis of a large variety of 1,2dihydronaphthalenes. ${ }^{[4]}$

For instance, the group of Gaunt has recently reported an elegant Cu-catalyzed alkyne carboarylation that enabled efficient synthesis of a large variety of a dihydronaphthalenes 1 (Scheme 1). ${ }^{[5]}$ To obtain the corresponding aromatic derivatives 2, a stoichiometric amount of DDQ has been used as an oxidant at high temperature (reflux in toluene). ${ }^{[5]}$

In view of the importance of these aromatic molecules, in particular in material science, the development of a practically simple, mild and efficient method is naturally appealing. Because the dehydrogenation of 1 involves two proton-two electron process, we reasoned that this could be accomplished photochemically by the association of an oxidant and a photocatalyst under visible light irradiation. ${ }^{[6]}$ Indeed, the generation of a highly reactive radical through monoelectronic reduction of an oxidant would enable a hydrogen atom transfer from 1 to form a benzylic radical. The latter can then be oxidized by the oxidized form of the photocatalyst to give rise to the corresponding carbocation that yields 2 after fast deprotonation step.

F. Rammal, Prof. Dr. A.-C. Gaumont, Dr. S. Lakhdar Normandie Univ., LCMT, ENSICAEN, UNICAEN, CNRS,

6, Boulevard Maréchal Juin, Caen 14000 France

E-mail : sami.lakhdar@ensicaen.fr

URL: http://www.Icmt.ensicaen.fr/ 


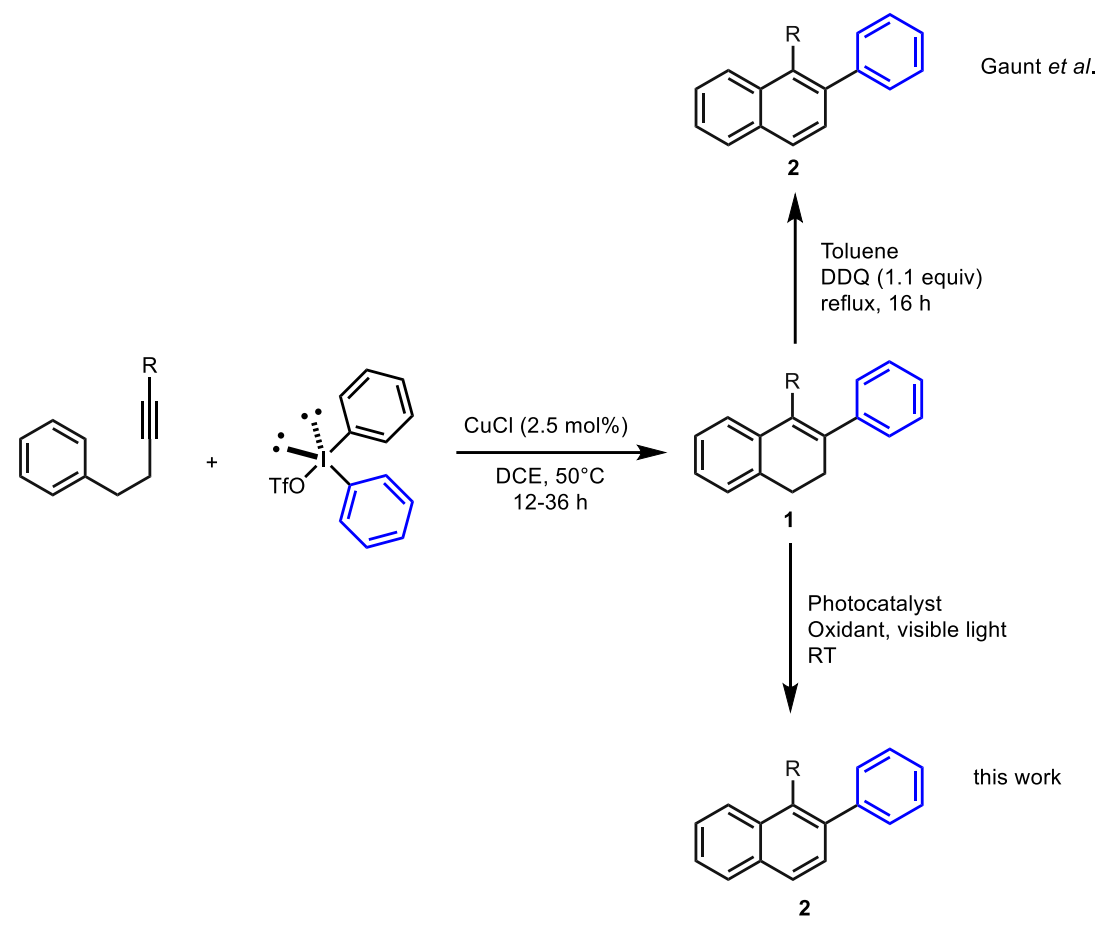

Scheme 1. Aromatization of 1,2-dihydronaphthalenes.

\section{Results and discussion}

To test this hypothesis, we first investigated the aromatization of $\mathbf{1 a}$ in the presence of a photocatalyst, and oxidant under visible light irradiation (Table 1). While the use of different photocatalysts such as Eosin $\mathrm{Y}$ (entry 2, 41\%), Ru(bpy) ${ }_{3}{ }^{2+}$ (entry 3, 45\%) and Rose Bengal (entry $4,6 \%$ ) in ethyl acetate gave moderate to low conversion, the use of 9-Mesityl-10methylacridinium (Mes-Acr), commonly known as Fukuzumi photocatalyst, ${ }^{[7]}$ gave almost quantitative conversion (99\%, entry 1$)$. With the aim to use environmentally begin oxidant for our photoreaction, we have first tested $\mathrm{O}_{2}$. Although good yield was isolated (81\%, entry 5 ), the reaction was found to be less efficient with other dihydronaphthalenes. The use of phenyldiazonium salt as an oxidant yielded the desired aromatic compound but in only $72 \%$ (entry 6). Interestingly, decreasing the catalyst loading to 2.5 mol\% didn't affect the efficiency of the reaction (entry 7). Different solvents have also been tested and even though fair to good conversions have been obtained $(42-72 \%$, entries $8-11)$, they remained lower than that obtained in EtOAc (entry 7). Finally, the importance of the photocatalyst (Mes-Acr) has been elucidated as only $16 \%$ of conversion has been observed when it was removed from the reaction (entry 14 ). 
Table 1. Survey of reaction conditions tor the photoredox-catalyzed dehydrogenation of $1 \mathrm{a}$.

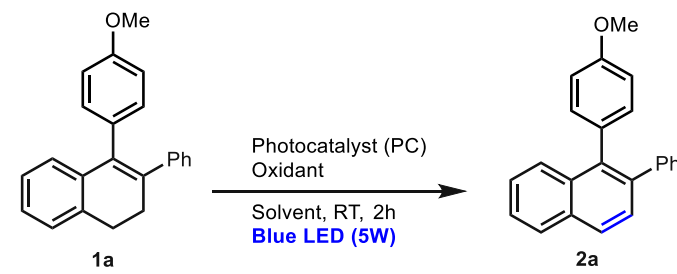

\begin{tabular}{|c|c|c|c|c|c|}
\hline & $\begin{array}{c}\text { Oxid } \\
\text { ant }\end{array}$ & PC & $\begin{array}{c}\mathrm{PC} \\
\text { loadin } \\
\mathrm{g} \\
\mathrm{m} \text { molin }\end{array}$ & $\begin{array}{c}\text { Solv } \\
\text { ent }\end{array}$ & $\begin{array}{l}\text { Yie } \\
\text { ld } \\
{[\%]} \\
{\left[\begin{array}{l}0 \\
{[}\end{array}\right]}\end{array}$ \\
\hline 1 & $\mathrm{Ph}_{2} \mathrm{I}^{+}$ & Mes-Acr & 5 & $\mathrm{AcO}$ & 99 \\
\hline 2 & $\left.\mathrm{Ph}_{2}\right|^{+}$ & Eosin $Y$ & 5 & $\mathrm{AcO}$ & 41 \\
\hline 3 & $\mathrm{Ph}_{2} \mathrm{I}^{+}$ & $\mathrm{Ru}(\mathrm{bpy})_{3}{ }^{2}$ & 5 & $\mathrm{AcO}$ & 45 \\
\hline 4 & $\mathrm{Ph}_{2} \mathrm{I}^{+}$ & Rose & 5 & $\mathrm{AcO}$ & 6 \\
\hline 5 & $\mathrm{O}_{2}$ & Mes-Acr & 5 & $\mathrm{AcO}$ & 81 \\
\hline 6 & $\mathrm{PhN}_{2}$ & Mes-Acr & 5 & $\mathrm{AcO}$ & 72 \\
\hline 7 & $\mathrm{Ph}_{2} \mathrm{l}^{+}$ & Mes-Acr & 2.5 & $\mathrm{AcO}$ & 99 \\
\hline 8 & $\mathrm{Ph}_{2} \mathrm{I}^{+}$ & Mes-Acr & 2.5 & DCM & 42 \\
\hline 9 & $\mathrm{Ph}_{2} \mathrm{I}^{+}$ & Mes-Acr & 2.5 & $\mathrm{MeC}$ & 48 \\
\hline 1 & $\mathrm{Ph}_{2} \mathrm{I}^{+}$ & Mes-Acr & 2.5 & Tolu & 70 \\
\hline 1 & $\mathrm{Ph}_{2} \mathrm{I}^{+}$ & Mes-Acr & 2.5 & DCE & 72 \\
\hline 1 & $\mathrm{Ph}_{2} \mathrm{I}^{+}$ & Mes-Acr & 2.5 & DMF & 57 \\
\hline 1 & $\left.\mathrm{Ph}_{2}\right|^{+}$ & Mes-Acr & 2.5 & THF & 23 \\
\hline 1 & $\mathrm{Ph}_{2} \mathrm{I}^{+}$ & - & - & $\mathrm{AcO}$ & 16 \\
\hline
\end{tabular}

[a] NMR yields have determined by ${ }^{1} \mathrm{H}$ NMR spectroscopy by refereeing to methoxy group signal of 1 . ${ }^{[b]}$ Triflate was used as a couterion.

With the optimization conditions in hand, we have next examined the scope of the reaction by testing the compatibility of the developed methodology with various 1,2-diarylnaphthalenes 1 bearing different substituents. As depicted in Figure 1, good to excellent yields (67-99\%) have been obtained with diarylnaphthalenes bearing electron-acceptors $(\mathbf{2} \mathbf{b}-\mathbf{f})$ or -donor $\mathbf{2} \mathbf{g}$ at the aromatic ring at the C2-position. More importantly, the method tolerates some functionalities such as halogens $(\mathbf{2 b}-\mathbf{d})$ and carbonyls $(\mathbf{2 e}, \mathbf{f})$. Similarly, the reaction works well with aromatic bearing a trifluoromethyl group at the meta position $(\mathbf{2} \mathbf{h}, \mathbf{9 9} \%)$. We have next examined the effect of the aromatic ring of the dihydronaphthalene on the photoredox aromatization reaction. As shown in Figure 1, the electronic nature of the substituent does not affect the performance of the reaction and naphthalenes (2i-I) have been isolated in good yields (55-86\%). Finally, the efficiency of the method has been tested with dihydronaphthalenes bearing other substituents than the para-methoxyphenyl at the $\mathrm{R}$ position (Figure 1). Delightfully, the polyaromatic naphthalenes have been isolated in good yields (2m-0; 56-99\%). 


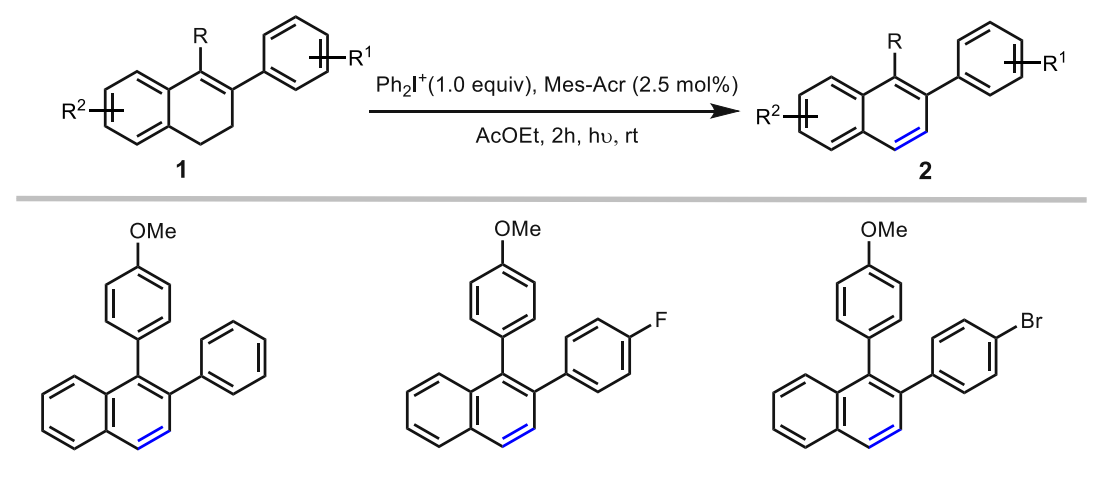

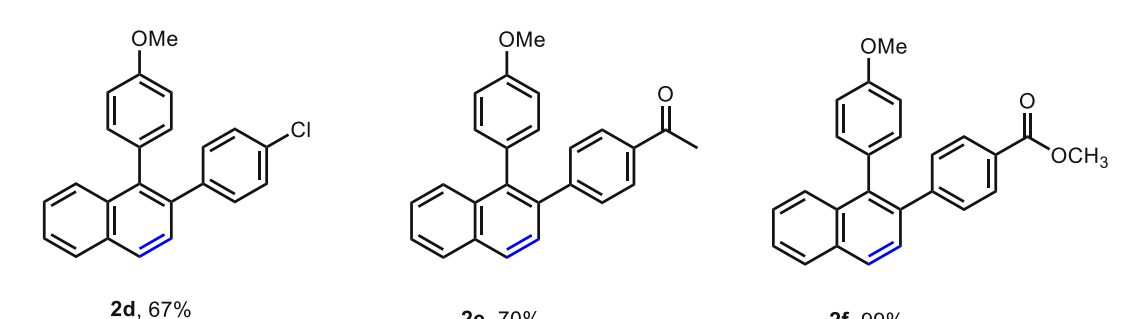

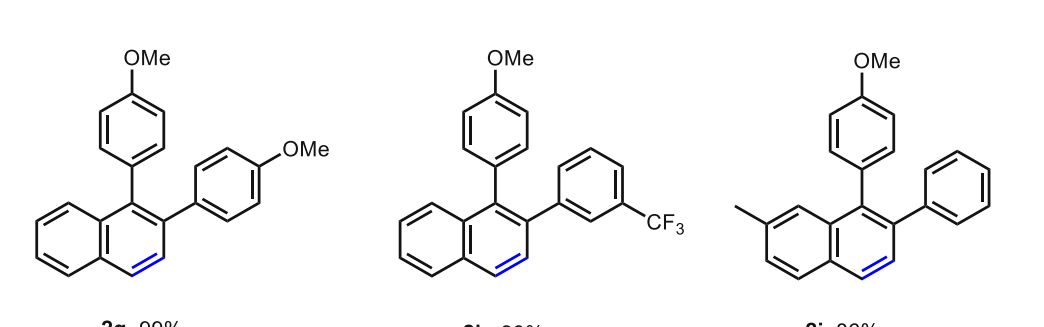

$$
\begin{aligned}
& 2000000 \\
& \text { of o }
\end{aligned}
$$

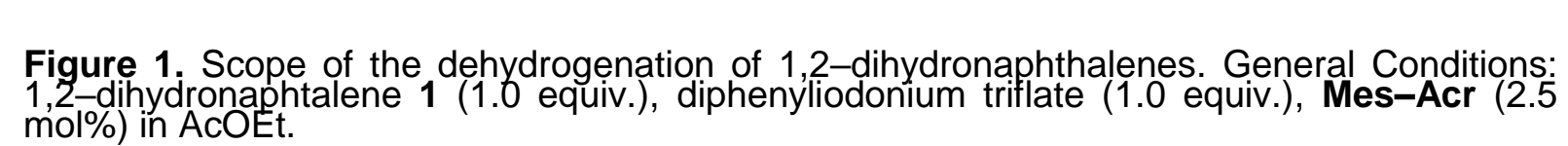

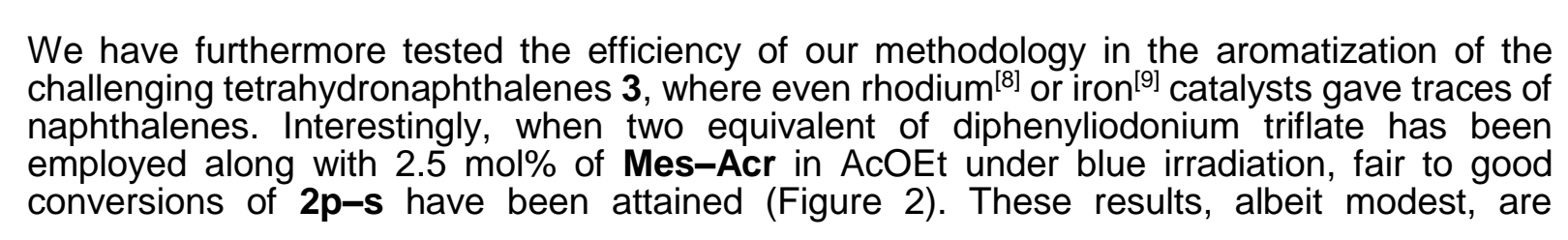


encouraging and even comparable to those recently reported by Kanai et al. ${ }^{[10]}$ when using a binary hybrid catalyst system comprising Mes-Acr and a palladium metal catalyst.<smiles>[R]c1ccc2c(c1)CCCC2[R]</smiles>

3

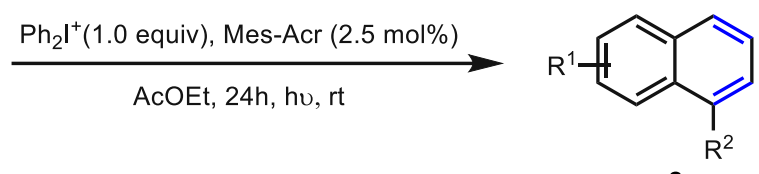

2<smiles>Cc1cccc2c(C)cccc12</smiles>

2s; $30 \%$

Figure 2. Aromatization of tetrahydronaphthalenes 3. General Conditions: tetrahydronaphthalenes 3 (1.0 equiv.), diphenyliodonium triflate $(2.0$ equiv.), Mes-Acr $(2.5$ mol\%) in AcOEt. Conversions are determined by $1 \mathrm{H}$ NMR spectroscopy by using tetrachloroethane as internal standard.

In order to gain insights into the reaction mechanism of the photooxidation, we first followed kinetics of the formation of 2a with $\mathrm{Ph}_{2} \mathrm{l}^{+}$and in the presence of different photocatalysts (see Figure S3, supporting information, Page S7). Interestingly, while almost $40 \%$ of conversion have been attained after 5 hours with both Eosin $\mathrm{Y}$ and $\mathrm{Ru}(\mathrm{bpy}){ }_{3}{ }^{2+}$, a quantitative formation of 2a within less than $5 \mathrm{~h}$ has been observed when Mes-Acr has been employed as a photocatalyst. This shows clearly the performance of the latter in the aromatization reaction, which we attribute the high oxidizing ability of [Mes-Acr] ${ }^{++}$, which is higher than those of the other photocatalysts (Table 1, entries 1-3) ${ }^{[11]}$

Experiments using either TEMPO as additive resulted in complete inhibition of the aromatization reaction, suggesting that radical intermediates were involved. 


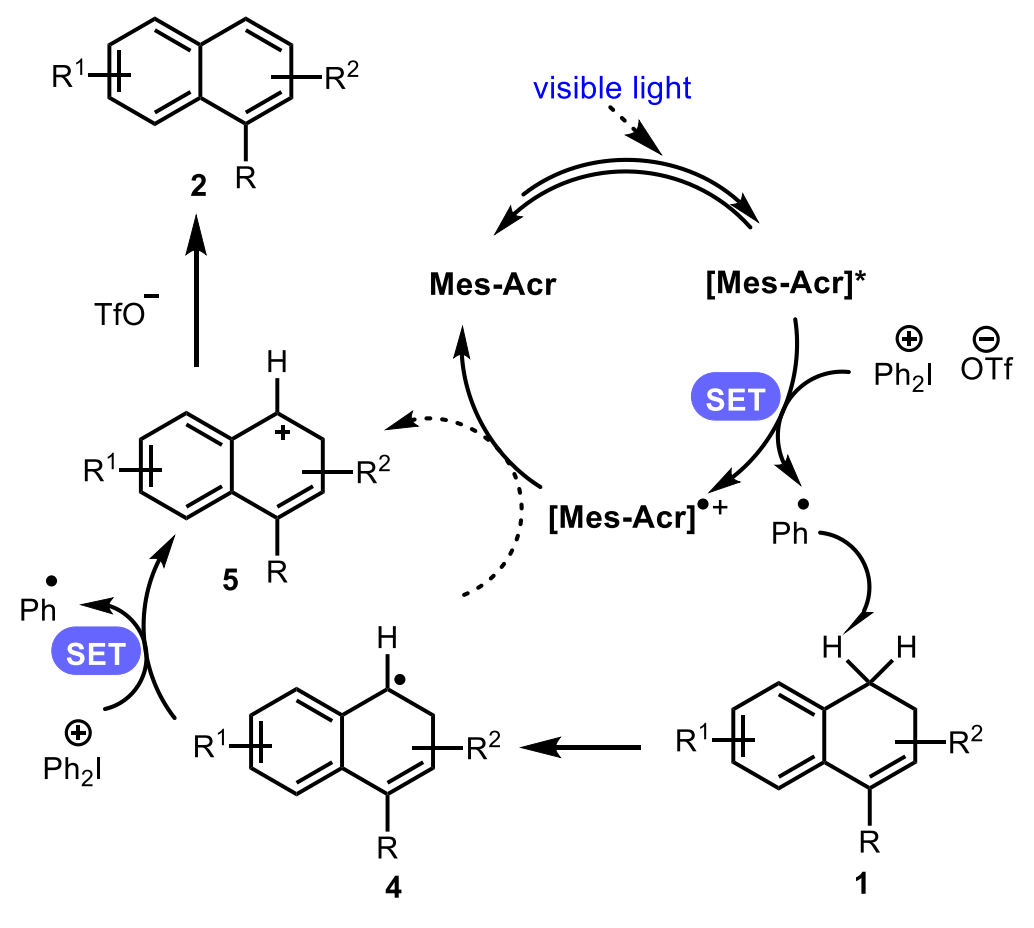

Figure 3. Proposed reaction mechanism.

Based on our previous work ${ }^{[11 \mathrm{a}]}$ and recent contributions by Wu and Lei, respectively ${ }^{[11 \mathrm{~b}, \mathrm{c}]}$ we hypothesize that the excited form of $\left(\right.$ Mes-Acr) ${ }^{*}$ reduce $\mathrm{Ph}_{2} \mathrm{l}^{+}$to generate the phenyl radical that abstracts a hydrogen from the 1,2-dihydronaphthalene to form the benzylic radical 4 . At this stage, an oxidation of the latter can take place either with the oxidative form of the photocatalyst or with the diphenyliodonium salt present in the media.To discriminate between both pathways, we determined quantum yield (QY) of the aromatization reaction of 1a by following a protocol previously reported by Yoon. ${ }^{[12]}$ With a QY of 11.5, it is likely that a radical chain mechanism is operative in this reaction (Figure 3). Because the aromatization of the carbocation must be a driving force of the reaction, a fast deprotonation take place with triflate to give rise to 2 .

In order to confirm the formation of the carbocation as intermediate in the reaction, we carried out the reaction of $\mathbf{1 a}$ with diphenyliodonium triflate in the presence of different nucleophiles (amides, thiol, etc...). Unfortunately, all these attempts to trap the carbocation with nucleophiles have failed, obviously due to the rapid deprotonation of the cation $\mathbf{4}$ as stated above. However, when 1,3,5-cycloheptatriene or 4,4'-methylene-bis ( $N, N$-dimethylaniline) have been submitted to our photooxidative conditions, the formation of the corresponding stabilized carbocations have been unambiguously elucidated by both ${ }^{1} \mathrm{HNMR}$ and UV-visible spectroscopy (see supporting information). ${ }^{[13]}$

\section{Conclusion}

In conclusion, we have developed a photoredox-catalyzed aromatization of 1,2dhydronaphthalene. This process is efficient, tolerates functionalities and takes place under mild conditions. Furthermore, the aromatization of four tetrahydronaphthalenes have been disclosed under our optimized conditions. Mechanistic investigations have been performed and allowed the suggestion of a reasonable reaction mechanism, where the formation of a benzylic carbocation as a key reactive intermediate is proposed. This new approach for the generation of high reactive cation may open new avenues for the formation of carbon-carbon and carbon-heteroatom bonds. This work is underway in our laboratory.

\section{Experimental Section}


General procedure: A schlenk tube was charged with the dihydronaphthalene 2 (1.0 equiv.) Mes-Acr $(2.5 \mathrm{~mol} \%)$ and diphenyliodonium triflate $(1.0$ equiv.) in ethyl acetate $(0.1 \mathrm{M})$. The reaction mixture was stirred at room temperature for two hours under blue LED irradiation $(5 \mathrm{~W})$. The solvent was removed in vacuo and the crude residue was purified by flash chromatography 99:1 ( $n$-pentane/ AcOEt) to yield the desired product.

\section{Acknowledgments}

The authors thank the LABEX SynOrg (ANR-11-LABX-0029) for financial support. F. R. is $\mathrm{i}$ indebted to the French Ministry of Research for a doctoral fellowship.

Keywords: aromatization $\bullet$ mechanisms $\bullet$ photoredox catalysis $\bullet$ radicals

[1] For a review, see: K. Itami, Pure Appl. Chem. 2012, 84, 907-916.

2. For a review, see: C. B. de Koning, A. L. Rousseau, W. A. L van Otterlo, Tetrahedron, 2003, 59, 7-36.

[3] For reviews, see: a) N. E. Shore, Chem. Rev.1988, 88, 1081-1119; b) S. Saito, Y. Yamamoto, Chem. Rev. 2000, 100, 2901-2916.

[4] For selected examples, see: a) S. Perveen, Z. Zhao, G. Zhang, J. Liu, M. Anwar, X. Fang, Org. Lett. 2017, 19, 2470-2473; b) Y.-H. Cho, V. Zunic, H. Senboku, M. Ölsen, M. Lautens, J. Am. Chem. Soc. 2006, 128, 6837-6846; c) R. Webster, C. Boing, M. Lautens, J. Am. Chem. Soc. 2009, 131, 444-445; d) F. Yang, J. Chen, J. Xu, F. Ma, Y. Zhou, M. V. Shinde, B. Fan, Org. Lett. 2016, 18, 4832-4835.

[5] A. J. Walkinshaw, W. Xu, M. G. Suero, M. J. Gaunt, J. Am. Chem. Soc.

2013, 135, 12532-12535.

[6] For recent reviews on photoredox catalysis, see: a) T. P. Yoon, M. A. Ischay, J. Du, Nat. Chem. 2010, 2, 527; b) J. M. R. Narayanam, C. R. J. Stephenson, Chem. Soc. Rev. 2011, 40, 102; c) J. Xuan, W. Xiao, Angew. Chem. 2012, 124, 6934-6944; Angew. Chem. Int. Ed. 2012, 51, 6828-6838; d) L. Shi, W.-J. Xia, Chem. Soc. Rev. 2012, 41, 7687-7697; e) D. Ravelli, M. Fagnoni, ChemCatChem 2012, 4, 169-171; f) Y. Xi, H. Yi, A. Lei, Org. Biomol. Chem. 2013, 11, 2387-2403; g) R. A. Angnes, Z. Li, C. R. D. Correia, G. B. Hammond, Org. Biomol. Chem. 2015, 13, 9152-9167; h) Skubi, K. L.; Blum. T. R.; Yoon, T. P. Chem. Rev. 2016, 116, $10035-$ 10074; i) X. Lang, J. Zhao, X.-d. Chen, Chem. Soc. Rev. 2016, 45, 3026-3038; j) M. Parasram, V. Gevorgyan, Chem. Soc. Rev. 2017, 46, 6227-6240; k) K. N. Lee, M.-Y. Ngai, Chem. Commun. 2017, 53, 13093-13112; I) Y. - Q. Zou, F. M. Hoermann, T. Bach, Chem. Soc. Rev. 2018, 47, 278-290; m) L. Marzo, S. K. Pagire, O. Reiser, B. König, Agew. Chem. 2018, 130, 10188-10228; Angew. Chem. Int. Ed. 2018; 57, 10034-10072; n) S. P. Pitre, C. D. McTiernan, J. C. Scaiano, Acc. Chem. Res. 2016, 49,1320-1330.

[7] For recent reviews on the use of the Fukuzumi photocatalyst in photoredox catalysis, see: a) S. Fukuzumi, K. Ohkubo, Org. Biomol. Chem. 2014, 12, 6059-6071; b) N. A. Romero, D. A. Nicewicz, Chem. Rev. 2016, 116, 10075-10166.

[8] A. D. Chowdhury, N. Weding, J. Julis, R. Franke, R. Jackstell, M. Beller, Angew. Chem. Int. Ed. 2014, 53, 6477-6481; b) A. D. Chowdhury, J. Julis, K. Grabow, B. Hannebauer, U. Bentrup, M. Adam, R. Franke, R. Jackstell, M. Beller, M. ChemSusChem 2015, 8, 323-330.

[9] S. Chakraborty, W. W. Brennessel, W. D. Jones, J. Am. Chem. Soc. 2014, 136, 85648567.

[10] S. Kato, Y. Saga, M. Kojima, H. Fuse, S. Matsunaga, A. Fukatsu, M. Kondo, S. Masaoka, M. Kanai, J. Am. Chem. Soc. 2017, 139, 2204-2207.

[11] a) G. Fausti, F. Morlet-Savary, J. Lalevée, A.-C. Gaumont, S. Lakhdar, Chem. Eur. J. 2017, 23, 2144-2148; b) M. Xiang, Z.-K.Xin, B. Chen, C.-H. Tung, L.-Z. Wu, Org. Lett. 2017, 19, 3009-3012; c) S. Wang, J. Liu, L. Niu, H. Yi, C. W. Chiang, A. Lei, J. Photochem. Photobiol., $A, 2018,355,120-124$.

[12] M. A. Cismesia, T. P. Yoon, Chem. Sci. 2015, 6, 5426-5434. 
[13] R. J. Mayer, N. Hampel, P. Mayer, A. R. Ofial, H. Mayr, Eur. J. Org. Chem. 2019, 412421. 